\title{
HUBUNGAN PENGAMBILAN KEPUTUSAN DENGAN KEBERHASILAN USAHA KEMITRAAN AYAM RAS PEDAGING DI KABUPATEN TABANAN
}

\author{
MAHARDIKA, C. B. D. P.1) ${ }^{\text {) I N. SUPARTA }}{ }^{2)}$, DAN N. W. T. INGGRIATI ${ }^{2)}$ \\ 1) Program Studi Magister Ilmu Peternakan, Universitas Udayana \\ 2) Fakultas Peternakan, Universitas Udayana \\ e-mail: cokbagusdharma@gmail.com
}

\begin{abstract}
ABSTRAK
Penelitian ini bertujuan untuk mengetahui tingkat keberhasilan usaha kemitraan dan kemampuan pengambilan keputusan pada manajemen pemeliharaan serta menganalisis hubungan pengetahuan, sikap, motivasi, persepsi dan interaksi sosial dengan pengambilan keputusan dan keberhasilan usaha kemitraan dan dilakukan di Kabupaten Tabanan. Responden penelitian sebanyak 122 peternak plasma. Pengambilan sampel menggunakan metode stratifikasi secara proporsional. Teknik analisis data yang digunakan dalam penelitian ini adalah SEM$P L S$. Hasil penelitian menunjukkan bahwa tingkat keberhasilan usaha kemitraan ayam ras pedaging di Kabupaten Tabanan berada pada tingkat sedang dan peternak plasma sudah mampu melakukan pengambilan keputusan yang baik tentang manajemen pemeliharaan. Pengetahuan, sikap dan persepsi peternak plasma berpengaruh positif nyata terhadap pengambilan keputusan manajemen usaha kemitraan ayam ras pedaging, sedangkan motivasi dan interaksi sosial tidak berpengaruh nyata. Pengambilan keputusan manajemen pemeliharaan berpengaruh positif nyata terhadap keberhasilan usaha kemitraan.
\end{abstract}

Kata kunci: ayam ras pedaging, keberhasilan, pengambilan keputusan

\section{MAKING RELATIONSHIP WITH THE SUCCESS OF BROILER CONTRACT FARMING AT TABANAN REGENCY}

\begin{abstract}
This research aims at determining the successful level of broiler contract farming and management decisionmaking ability. In addition, it was also conducted with the correlation of knowledge, attitude, motivation, perception and social interaction of farmers with the success of decision making and broiler contract farming. The research was carried out at Tabanan regency. There were 122 farmers as respondents using proportionate stratified random sampling and analyzed using by SEM-PLS. It showed that the successful level of broiler contract farming on middle level and most of farmers have abilities to make a good decision on broiler management. Knowledge, attitude and perception have positive significantly for decision making of broiler management, but motivation and social interaction had not significantly effected. Decision making gave positive effect to the success broiler contract farming.
\end{abstract}

Keywords: broiler, success, decision making

\section{PENDAHULUAN}

Perkembangan industri ayam ras pedaging telah mengarah terbentuknya suatu industri dengan pendekatan integrasi vertikal manajemen perusahaan multinasional maupun melalui kemitraan usaha. Pendekatan integrasi vertikal tersebut memiliki tujuan untuk meningkatkan efisiensi dan daya saing produk ayam ras pedaging di pasar domestik maupun global (Saptana dan Daryanto, 2013). Namun demikian, sampai saat ini tantangan dalam menjalankan usaha kemitraan oleh peternak plasma cukup banyak mengalami kendala. Perusahaan kemitraan (inti) dirasakan lebih besar memegang kendali usaha dibandingkan dengan peternak plasma, harga kontrak sepenuhnya dirumuskan dan dikendalikan oleh perusahaan inti.

Kendala di lapangan secara garis besar dapat terlihat dari harga kontrak yang dapat berubah sesuai dengan kepentingan perusahaan, pengambilan keputusan cukup terhambat saat melakukan pemeliharaan dan keputusan strategis lainnya seperti penentuan kualitas sapronak, kecepatan pembayaran hasil dan pelayanan 
penyuluhan. Rendahnya posisi tawar menawar dan terkadang masih kurang transparan dalam penentuan harga input maupun output. Ketidakberdayaan dalam mengontrol kualitas sapronak menyebabkan kerugian bagi peternak plasma, sehingga menghadapi permasalahan pada pola kemitraan. Peternak plasma harus mampu memprioritaskan kualitas manajemen pemeliharaan ayam ras pedaging. Menurut Sujak (2007), keterampilan manajemen usaha dilihat dari keberanian peternak dalam mengambil keputusan dalam memecahkan masalah.

Menurut pendapat Purnaningsih (2006), konsep kemitraan yang berkelanjutan adalah mengacu kepada konsep meminimalkan risiko dengan memaksimalkan kekuatan-kekuatan melalui upaya kerjasama antar pelaku usaha (peternak plasma dan perusahaan kemitraan) untuk mencapai keberhasilan. Adanya kemampuan menganalisis kualitas sapronak, disiplin, manajemen yang andal dan penerapan biosekuriti yang memadai akan menambah kekuatan untuk menyikapi tantangan dan kendala dalam bermitra usaha. Purnaningsih (2006) juga menambahkan bahwa kewenangan peternak plasma dalam mengambil keputusan dalam berusaha tani-ternak akan memotivasi untuk pengelolaan usaha dan produktivitasnya.

Tujuan dari penelitian ini adalah (1) mengetahui tingkat keberhasilan usaha kemitraan ayam ras pedaging di Kabupaten Tabanan, (2) mengetahui kemampuan pengambilan keputusan peternak plasma dalam manajemen pemeliharaan, (3) menganalisis hubungan pengetahuan, sikap, motivasi, persepsi dan interaksi sosial dengan pengambilan keputusan dan keberhasilan usaha kemitraan ayam ras pedaging di Kabupaten Tabanan, (4) menganalisis pengaruh pengambilan keputusan manajemen pemeliharaan terhadap keberhasilan usaha kemitraan ayam ras pedaging, dan (5) menganalisis pengaruh yang paling dominan diantara pengetahuan, sikap, motivasi, persepsi, interaksi sosial dan pengambilan keputusan terhadap keberhasilan usaha kemitraan ayam ras pedaging di Kabupaten Tabanan.

\section{METODE PENELITIAN}

\section{Desain Penelitian}

Penelitian ini merupakan penelitan yang dirancang sebagai explanatory research design yaitu menjelaskan dan menganalisis hubungan antara variabel-variabel penelitian yang akan didesain menggunakan teknis analisis Partial Least Square (PLS). Variabel penelitian yang diamati adalah keberhasilan usaha peternakan pada kemitraan ayam ras pedaging, pengambilan keputusan, pengetahuan, sikap, motivasi, persepsi serta interaksi sosial.

\section{Lokasi dan Waktu Penelitian}

Penelitian ini dilaksanakan di Kabupaten Tabanan pada peternak plasma kemitraan ayam ras pedaging yaitu pada bulan Desember tahun 2016 sampai Januari tahun 2017. Lokasi penelitian ditentukan dengan metode purposif yaitu penentuan daerah yang didasarkan pada pertimbangan tertentu (Singarimbun dan Effendi, 2006). Dasar pertimbangan yang digunakan untuk memilih lokasi penelitian adalah karena populasi ternak ayam ras pedaging di Kabupaten Tabanan terbanyak dari seluruh kabupaten/kota di Provinsi Bali, sehingga diperkirakan cukup banyak masyarakat yang melakukan usaha peternakan ayam ras pedaging.

\section{Sampel Penelitian}

Penentuan sampel sebagai responen dalam penelitian ini dilakukan secara acak dengan teknik distratifikasi proporsional (proportionate stratified random sampling). Teknik sampling distratifikasi proporsional adalah teknik pengambilan sampel melalui proses pembagian populasi kedalam strata dan memilih sampel acak dari setiap strata tersebut secara proporsional (Singarimbun dan Effendi, 2006). Menurut survai awal, estimasi produksi chick-in masing-masing inti dan pemetaan internal perusahaan kemitraan pada tahun 2016, total populasi mitra inti besar mencapai 398 peternak dan total populasi mitra inti kecil mencapai 207 peternak. Pengambilan sampel dalam inti besar dan inti kecil distratifikasi berdasarkan skala usahanya (2.000-15.00o ekor) masing-masing $15 \%$ untuk inti besar dan 30\% untuk inti kecilsehingga total sampel yang diamati adalah 122 peternak (Tabel 1).

Tabel 1. Penentuan responden dari populasi sasaran

\begin{tabular}{ccc}
\hline Skala usaha*(ekor) & Inti besar & Inti kecil \\
\hline $2.000-6.000$ & $263 \times 15 \%=40$ peternak & $146 \times 30 \%=44$ peternak \\
$>6.000-10.000$ & $97 \times 15 \%=15$ peternak & $50 \times 30 \%=15$ peternak \\
$>10.000-15.000$ & $35 \times 15 \%=5$ peternak & $10 \times 30 \%=3$ peternak \\
Total sampel & 60 peternak & 62 peternak \\
\hline
\end{tabular}

Keterangan:

Keseluruhan populasi mitra inti adalah 605 plasma. Skala usaha plasma $<2.000$ dan $>$ 15.000 ekor jumlahnya terlalu sedikit (pencilan), sehingga ditentukan populasi sasarannya dengan skala usaha 2.000-15.000 ekor (601 plasma).

\section{Jenis, Sumber dan Pengumpulan Data}

Jenis data yang digunakan dalam penelitian ini adalah data primer dan sekunder. Data primer adalah data yang belum pernah diolah oleh pihak tertentu untuk suatu kepentingan. Data primer dalam penelitian ini bersumber dari sumber primer atau pihak pertama yang memiliki suatu data (Abdillah dan Jogiyanto, 2015). Pengumpulan data primer dilakukan dengan empat cara yaitu wawancara langsung, wawancara mendalam, observasi dan dokumentasi.

Data sekunder merupakan data yang telah diolah, 
disimpan dan disajikan dalam bentuk tertentu seperti data gambaran umum Kabupaten Tabanan dan populasi mitra ayam ras pedaging. Data sekunder diperoleh dari pihak kedua yaitu Badan Pusat Statistik Provinsi Bali, Dinas Peternakan dan Kesehatan Hewan Provinsi Bali, dan PT. Ciomas Adisatwa.

\section{Pengukuran Variabel}

Variabel pengetahuan $\left(\mathrm{X}_{1}\right)$, sikap $\left(\mathrm{X}_{2}\right)$, motivasi $\left(\mathrm{X}_{3}\right)$, persepsi $\left(\mathrm{X}_{4}\right)$, interaksi sosial $\left(\mathrm{X}_{5}\right)$, pengambilan keputusan $\left(\mathrm{Y}_{1}\right)$ dan keberhasilan usaha kemitraan ayam ras pedaging $\left(\mathrm{Y}_{2}\right)$ ditabulasi dan diukur seluruh indikator dari variabel penelitian menggunakan skala berjenjang lima $(1,2,3,4$, dan5). Variabel yang sudah diberikan skor diklasifikasikan menjadi lima kategori yaitu sangat tinggi, tinggi, sedang, rendah dan sangat rendah atau sangat baik, baik, sedang, buruk dan sangat buruk. Untuk pernyataan positif, respon sangat tinggi dan sangat baik diberi skor lima, sedangkan respon sangat rendah dan sangat buruk diberi skor satu. Demikian juga sebaliknya, untuk pernyataan negatif, respon sangat rendah dan sangat buruk diberi skor lima, sedangkan respon sangat tinggi dan sangat baik diberi skor satu (Singarimbun dan Effendi, 2006).

\section{Analisis Data}

Analisis data dalam penelitian ini menggunakan statistika deskriptif dan statistika inferensia. Statistika deskriptif sebagai metode yang berkaitan dengan pengumpulan, penyajian dan peringkasan suatu gugus data sehingga memberikan informasi yang berguna. Statistika deskriptif disajikan dalam bentuk frekuensi, distribusi frekuensi, persentase dan rataan skor. Statistika inferensia digunakan untuk menjelaskan besar hubungan antara variabel bebas dengan variabel terikat dan digunakan untuk menguji kebenaran hipotesis dari suatu penelitian untuk mencapai tujuan penelitian. Teknik analisis data yang digunakan dalam penelitian ini adalah Structural Equation Modelling (SEM) berbasis varian yang dikenal dengan Partial Least Square (PLS).

\section{HASIL DAN PEMBAHASAN}

\section{Evaluasi Deskriptif}

Hasil penelitian menunjukan bahwa 51,64\% peternak plasma memiliki pengetahuan yang tinggi tentang hal-hal yang berkaitan dengan usaha kemitraan ayam ras pedaging (Tabel 2). Hal ini sangat dimungkinkan karena peternak plasma cukup rutin berinteraksi dengan penyuluh pendamping dari pihak inti terkait dalam hal-hal perkembangan ilmu dan teknologi ayam ras pedaging.

Selain itu, 47,54\% peternak plasma memiliki
Tabel 2. Sebaran peternak plasma berdasarkan variabel penelitian

\begin{tabular}{lcccc}
\hline \multicolumn{1}{c}{ Variabel } & $\begin{array}{c}\text { Pencapaian } \\
\text { skor* }\end{array}$ & $\begin{array}{c}\text { Persentase } \\
(\%)^{* *}\end{array}$ & Rataan Skor & Kategori \\
\hline Pengetahuan & $>3,4-4,2$ & 51,64 & 3,50 & Tinggi \\
Sikap & $>3,4-4,2$ & 47,54 & 3,60 & Positif \\
Motivasi & $>3,4-4,2$ & 52,46 & 3,60 & Tinggi \\
Persepsi & $>3,4-4,2$ & 46,72 & 3,70 & Baik \\
Interaksi sosial & $>3,4-4,2$ & 44,26 & 3,50 & Tinggi \\
Pengambilan keputusan & $>3,4-4,2$ & 45,90 & 3,60 & Baik \\
Keberhasilan usaha & $>2,6-3,4$ & 40,16 & 3,20 & Sedang \\
\hline
\end{tabular}

Keterangan:

* Pencapaian skor: 1,0-1,8: Sangat rendah/Sangat buruk

$>1,8-2,6:$ Rendah/Buruk

$>2,6-3,4$ : Cukup/Sedang

$>3,4-4,2$ : Tinggi/Baik

$>4,2-5,0$ : Sangat tinggi/Sangat baik

**Persentase peternak plasma (total responden $=122$ orang)

perhatian dan respon positif tentang hal-hal yang berkaitan dengan usaha kemitraan ayam ras pedaging. Sikap positif ditunjukan dengan antusiasnya peternak plasma jika diberikan masukan atau saran terkait teknis produksi dan kooperatif dalam berbagai hal. Sebagian besar peternak plasma merasa termotivasi oleh kebutuhan dan harapannya dalam menjalankan usaha kemitraan (52,46\%). Motivasi yang tinggi mengindikasikan niat peternak plasma selalu bekerja dan berprestasi lebih baik agar cepat mencapai kebutuhan dan harapannya.

Pencapaian skor rata-rata untuk persepsi peternak plasma adalah sebesar 3,60 dan sebagian besar (46,72\%) mempunyai persepsi yang baik terhadap hal-hal yang berkaitan dengan usaha kemitraan ayam ras pedaging (Tabel 2). Hal ini berkaitan dengan kesamaan pandangan peternak plasma dengan persepsi perusahaan kemitraan tentang hak dan kewajiban dalam bermitra. Hak dan kewajiban bermitra mencantumkan aturan dan manfaat dalam bermitra usaha dengan maksud dan tujuan yang positif menguntungkan kedua belah pihak yaitu peternak plasma dan inti. Hasil penelitian juga menunjukkan bahwa telah terbinanya hubungan komunikasi interpersonal yang baik antar peternak plasma usaha kemitraan, saling berinteraksi dengan petugas penyuluh pendamping serta aktif dalam memanfaatkan media individual dan media massa sebagai salah satu media komunikasinya. Hal ini dilihat dari 44,26\% peternak plasma berinteraksi baik secara langsung maupun tidak langsung dengan individu lain khususnya petugas pendamping.

Pada Tabel 2, 45,90\% peternak plasma mengambil keputusan yang baik dalam manajemen usaha kemitraan terkait teknis pemeliharaan dengan mengikuti beberapa tahap mulai dari mengidentifikasi permasalahan hingga menentukan alternatif. Tingkat keberhasilan usaha peternak plasma ayam ras pedaging berada pada level sedang dengan tingkat deplesi berkisar 5-7\%, ratarata indeks prestasi 300 dan bobot panen pada umur 30 hari rata-rata berkisar $1,55 \mathrm{~kg} /$ ekor dengan FCR 
1,620. Dari segi pendapatan, rata-rata pendapatan mencapai $\mathrm{Rp} 1.500$ - Rp 2.000/ekor/periode dengan keuntungan bersih \pm Rp 700 - Rp 1.00o/ekor/periode. Hal ini mengindikasikan peternak plasma sudah cukup baik dan terampil dalam mengelola usaha kemitraan meskipun belum mencapai nilai yang maksimal.

\section{Evaluasi Model Pengukuran}

Model pengukuran dievaluasi dengan melihat validitas konvergen, diskriminan dan reliabilitas gabungan masing-masing indikator dan variabel. Hasil evaluasi validitas konvergen, semua indikator dikatakan valid karena memiliki nilai bobot pengukuran diatas 0,50 dengan nilai t-hitung diatas 1,96 (Tabel 3).

Tabel 3. Loading factor indikator variabel penelitian

\begin{tabular}{|c|c|c|c|}
\hline Variabel & Indikator/item & Bobot & t-hitung \\
\hline \multirow{4}{*}{$\begin{array}{l}\text { Pengetahuan } \\
\left(\mathrm{X}_{1}\right)\end{array}$} & Manajemen usaha kemitraan & 0,753 & 16,452 \\
\hline & Kualitas sapronak & 0,807 & 26,249 \\
\hline & Manajemen pemeliharaan & 0,787 & 21,262 \\
\hline & Analisis usaha kemitraan & 0,830 & 24,524 \\
\hline \multirow{3}{*}{$\begin{array}{l}\text { Sikap } \\
\left(X_{2}\right)\end{array}$} & Sikap dalam menentukan mitra usaha & 0,871 & 38,597 \\
\hline & Sikap dalam manajemen pemeliharaan & 0,901 & 57,679 \\
\hline & Sikap dalam menganalisis usaha kemitraan & 0,829 & 20,971 \\
\hline \multirow{3}{*}{ Motivasi $\left(\mathrm{X}_{3}\right)$} & Kebutuhan & 0,862 & 26,557 \\
\hline & Harapan & 0,889 & 34,459 \\
\hline & Dorongan & 0,706 & 9,225 \\
\hline \multirow{4}{*}{$\begin{array}{l}\text { Persepsi } \\
\left(\mathrm{X}_{4}\right)\end{array}$} & Persepsi tentang pola kemitraan & 0,828 & 24,261 \\
\hline & Persepsi tentang kualitas sapronak & 0,804 & 25,781 \\
\hline & Persepsi tentang manajemen pemeliharaan & 0,841 & 28,123 \\
\hline & Persepsi tentang analisis usaha & 0,801 & 20,134 \\
\hline \multirow{3}{*}{$\begin{array}{l}\text { Interaksi } \\
\text { Sosial }\left(X_{5}\right)\end{array}$} & Berinteraksi secara langsung & 0,831 & 15,385 \\
\hline & Berinteraksi secara tidak langsung & 0,881 & 21,461 \\
\hline & Identifikasi permasalahan & 0,911 & 54,628 \\
\hline \multirow{3}{*}{$\begin{array}{l}\text { Pengambilan } \\
\text { Keputusan } \\
\left(\mathrm{Y}_{1}\right)\end{array}$} & Mengembangkan kriteria pemecahan & 0,827 & 24,288 \\
\hline & Mengembangkan alternatif & 0,863 & 35,716 \\
\hline & Penentuan alternatif pemecahan masalah & 0,709 & 12,053 \\
\hline \multirow{2}{*}{$\begin{array}{l}\text { Keberhasilan } \\
\text { Usaha }\left(Y_{2}\right)\end{array}$} & Performa produksi & 0,962 & 124,356 \\
\hline & Pendapatan dan volume usaha & 0,958 & 105,781 \\
\hline
\end{tabular}

Nilai AVE variabel penelitian diatas 0,50. Hal ini berarti seluruh variabilitas yang terjadi pada indikatorindikator penelitian mampu dijelaskan lebih dari 50\% oleh variabilitas variabel laten daripada variabilitas yang ditimbulkan kesalahan pengukuran (Tabel 4).

Tabel 4. Nilai AVE dan perbandinganya dengan nilai korelasi variabel

\begin{tabular}{cccccccccc}
\hline $\begin{array}{c}\text { Varia- } \\
\text { bel }\end{array}$ & AVE & VAVE & $X_{1}$ & $X_{2}$ & $X_{3}$ & $X_{4}$ & $X_{5}$ & $Y_{1}$ & $Y_{2}$ \\
\hline$X_{1}$ & 0,632 & 0,795 & 1 & & & & & & \\
$X_{2}$ & 0,752 & 0,867 & 0,727 & 1 & & & & & \\
$X_{3}$ & 0,678 & 0,823 & 0,536 & 0,550 & 1 & & & & \\
$X_{4}$ & 0,670 & 0,819 & 0,793 & 0,692 & 0,526 & 1 & & & \\
$X_{5}$ & 0,733 & 0,856 & 0,436 & 0,465 & 0,558 & 0,511 & 1 & & \\
$Y_{1}$ & 0,691 & 0,831 & 0,727 & 0,788 & 0,520 & 0,788 & 0,504 & 1 & \\
$Y_{2}$ & 0,921 & 0,960 & 0,767 & 0,621 & 0,370 & 0,742 & 0,341 & 0,768 & 1 \\
\hline
\end{tabular}

Nilai akar dari average variance extracted ( $\mathrm{AVE}$ ) variabel laten lebih besar dari koefisien korelasi variabel laten lainnya. Hal ini mengindikasikan ketujuh variabel laten tersebut memiliki validitas diskriminan yang baik.

Tabel 5. Nilai composite reliability dan cronbach's alfa variabel laten

\begin{tabular}{lcc}
\hline \multicolumn{1}{c}{ Variabel laten } & Composite Reliability & Cronbach's Alpha \\
\hline Pengetahuan $\left(\mathrm{X}_{1}\right)$ & 0,873 & 0,805 \\
Sikap $\left(\mathrm{X}_{2}\right)$ & 0,901 & 0,836 \\
Motivasi $\left(\mathrm{X}_{3}\right)$ & 0,862 & 0,763 \\
Persepsi $\left(\mathrm{X}_{4}\right)$ & 0,891 & 0,836 \\
Interaksi $\left(\mathrm{X}_{5}\right)$ & 0,846 & 0,638 \\
Keputusan $\left(\mathrm{Y}_{1}\right)$ & 0,899 & 0,847 \\
Keberhasilan $\left(\mathrm{Y}_{2}\right)$ & 0,959 & 0,914
\end{tabular}

Hasil penelitian pada Tabel 5 , menunjukan semua blok indikator andal dalam mengukur variabel penelitian. Keseluruhan indikator konsisten dalam mengukur pengetahuan, sikap, motivasi, persepsi, interaksi sosial, pengambilan keputusan dan keberhasilan usaha di atas $70 \%$.

\section{Evaluasi Model Struktural}

Hasil evaluasi model struktural mendapatkan nilai $\mathrm{R}^{2}$ pada pengambilan keputusan dan keberhasilan usaha sebesar 0,784 dan 0,680 (Tabel 6). Menurut Hair et al. (2011), variabel $\mathrm{R}^{2}>0,670$ dikategorikan model prediksinya substansial. Hal ini berarti pengetahuan, sikap, motivasi, persepsi dan interaksi sosial substansial dalam memprediksi pengambilan keputusan dan keberhasilan usaha. Hasil evaluasi model struktural mendapatkan nilai $\mathrm{Q}^{2}$ pada model penelitian ini adalah sebesar 0,793 yang memiliki arti 79,3\% informasi dalam model yang dibangun sudah memiliki kesesuaian yang baik.

Tabel 6. Nilai composite reliability dan cronbach's alfa variabel laten

\begin{tabular}{lcc}
\hline \multicolumn{1}{c}{ Variabel laten } & $\mathrm{R}^{2}$ & $\mathrm{Q}^{2}$ \\
\hline Pengambilan Keputusan $\left(\mathrm{Y}_{1}\right)$ & 0,784 & \multirow{2}{*}{0,793} \\
Keberhasilan Usaha $\left(\mathrm{Y}_{2}\right)$ & 0,680 &
\end{tabular}

Keterangan: $Q^{2}=1-\left(1-R_{1}{ }^{2}\right)\left(1-R_{2}{ }^{2}\right)=0,793$

\section{Pengujian Hipotesis}

Hasil penelitian menunjukkan bahwa pengetahuan peternak plasma $\left(\mathrm{X}_{1}\right)$ terbukti berpengaruh sangat positif nyata $(\mathrm{P}<0,01)$ terhadap pengambilan keputusan manajemen pemeliharaan $\left(\mathrm{Y}_{1}\right)$ dan keberhasilan usaha kemitraan $\left(\mathrm{Y}_{2}\right)$. Hasil ini ditunjukkan dengan koefisien jalur bernilai positif dan t-hitung > t-tabel (Tabel 7). Hal ini dimungkinkan karena pengetahuan merupakan faktor yang membentuk perilaku peternak plasma yang banyak dipengaruhi oleh fungsi informasi (Thoha, 2007). 
Tabel 7. Hasil evaluasi validasi koefisien jalur secara parsial (uji-t)

\begin{tabular}{lcc}
\hline \multicolumn{1}{c}{ Hubungan antar variabel } & $\begin{array}{c}\text { Koefisien } \\
\text { Jalur }\end{array}$ & t-hitung \\
\hline Pengetahuan $\rightarrow$ Pengambilan keputusan & 0,392 & $3,769^{\mathrm{sn}}$ \\
Sikap $\rightarrow$ Pengambilan keputusan & 0,325 & $3,062^{\mathrm{sn}}$ \\
Motivasi $\rightarrow$ Pengambilan keputusan & $-0,037$ & $0,501^{\mathrm{tn}}$ \\
Persepsi $\rightarrow$ Pengambilan keputusan & 0,226 & $2,594^{\mathrm{sn}}$ \\
Interaksi sosial $\rightarrow$ Pengambilan keputusan & 0,086 & $1,385^{\mathrm{tn}}$ \\
Pengetahuan $\rightarrow$ Keberhasilan usaha & 0,331 & $2,803^{\mathrm{sn}}$ \\
Sikap $\rightarrow$ Keberhasilan usaha & $-0,029$ & $0,270^{\mathrm{tn}}$ \\
Motivasi $\rightarrow$ Keberhasilan usaha & $-0,100$ & $1,109^{\mathrm{tn}}$ \\
Persepsi $\rightarrow$ Keberhasilan usaha & 0,295 & $2,811^{\mathrm{sn}}$ \\
Interaksi Sosial $\rightarrow$ Keberhasilan usaha & $-0,073$ & $0,874^{\mathrm{tn}}$ \\
Pengambilan keputusan $\rightarrow$ Keberhasilan usaha & 0,373 & $2.900^{\mathrm{sn}}$ \\
\hline
\end{tabular}

Keterangan: ${ }^{s n}$ sangat nyata $(p<0,01)$, ${ }^{\text {tn }}$ tidak nyata $(p>0,05)$

Pada Tabel 7 , sikap peternak plasma $\left(\mathrm{X}_{2}\right)$ terbukti berpengaruh sangat positif nyata $(\mathrm{p}<0,01)$ terhadap pengambilan keputusan manajemen pemeliharaan $\left(\mathrm{Y}_{1}\right)$. Hasil ini ditunjukkan oleh koefisien jalur yang bernilai positif sebesar 0,325 dengan t-hitung sebesar 3,062 (t-hitung > 2,358). Hasil menerangkan bahwa jika sikap peternak plasma positif maka mereka akan cenderung melakukan pengambilan keputusan yang baik. Sikap yang didukung melalui pengambilan keputusan pada manajemen pemeliharaan menunjukan kesiapannya untuk bertindak sesuai dengan pemahaman terhadap objek tersebut (Gerungan, 2010).

Persepsi peternak plasma $\left(\mathrm{X}_{4}\right)$ terbukti berpengaruh sangat nyata $(\mathrm{P}<\mathrm{O}, 01)$ dan positif terhadap pengambilan keputusan manajemen pemeliharaan $\left(\mathrm{Y}_{1}\right)$ dan keberhasilan usaha kemitraan $\left(\mathrm{Y}_{2}\right)$. Hasil ini ditunjukkan oleh koefisien jalur yang bernilai positif dengan t-hitung $>\mathrm{t}$-tabel. Hubungan yang nyata ini mencerminkan bahwa penafsiran peternak plasma yang berkaitan dengan usaha kemitraanya terbukti mempengaruhi mereka mengambil suatu keputusan. Mulyana (2007) mengatakan bahwa semakin tinggi derajat kesamaan persepsi antara komunikator dengan pengguna, maka semakin mudah proses komunikasi itu karena inti dari komunikasi adalah persepsi.

Pengambilan keputusan manajemen pemeliharaan yang dilakukan peternak plasma $\left(\mathrm{Y}_{1}\right)$ terbukti berpengaruh sangat positif nyata $(\mathrm{P}<0,01)$ terhadap keberhasilan usaha kemitraan ayam ras pedaging $\left(\mathrm{Y}_{2}\right)$. Hasil ini ditunjukkan oleh koefisien jalur yang bernilai positif sebesar 0,373 dengan t-hitung sebesar 2,900 (t-hitung > 2,358). Hal ini sangat dimungkinkan karena peternak plasma bersikap proaktif untuk menanggulangi permasalahan yang terjadi. Sikap yang proaktif ditunjukan kecenderungan mengambil keputusan secara normatif sebagai upaya menghasilkan produksi yang optimal. Hal ini sesuai dengan pendapat Thoha (2007) yang mengatakan bahwa seseorang yang memiliki karakteristik berprestasi tinggi adalah orang yang senang dengan mengambil risiko moderat, senang merespon, peka, lebih memperhitungkan keberhasilan dan bekerja lebih efisien.

Tabel 8. Pengaruh langsung dan tidak langsung variabel penelitian dengan keberhasilan usaha kemitraan

\begin{tabular}{|c|c|c|c|c|c|c|}
\hline \multirow{3}{*}{$\begin{array}{l}\text { Variabel } \\
\text { penelitian }\end{array}$} & \multicolumn{6}{|c|}{ Pengaruh } \\
\hline & \multicolumn{2}{|c|}{ Langsung } & \multicolumn{2}{|c|}{ Tak langsung } & \multicolumn{2}{|c|}{ Total } \\
\hline & Nilai & $\%$ & Nilai & $\%$ & Nilai & $\%$ \\
\hline Pengetahuan & $0,331^{\text {sn }}$ & 69,1 & $0,148^{s n}$ & 31,9 & 0,479 & 100 \\
\hline Sikap & - & - & $0,123^{s n}$ & 100 & 0,123 & 100 \\
\hline Motivasi & - & - & - & - & - & - \\
\hline Persepsi & $0,295^{\mathrm{sn}}$ & 77,7 & $0,085^{s n}$ & 22,3 & 0,380 & 100 \\
\hline Interaksi sosial & - & - & - & - & - & - \\
\hline $\begin{array}{l}\text { Pengambilan } \\
\text { keputusan }\end{array}$ & $0,378^{s n}$ & 100 & - & - & 0,378 & 100 \\
\hline
\end{tabular}

Keterangan: ${ }^{\text {sn }}$ sangat nyata $(P<0,01)$

Pengambilan keputusan merupakan faktor yang dominan berpengaruh secara langsung tehadap keberhasilan usaha (Tabel 8). Hal ini berarti peternak plasma mengambil keputusan dalam menajemen akan sangat berdampak terhadap keberhasilan usaha. Menurut Suparta (2001), sifat pengambil risiko selalu memperhitungkan kemungkinan keberhasilan dan kegagalan dalam pelaksanaan kegiatan untuk mencapai tujuan.

Pengetahuan, sikap dan persepsi mempunyai hubungan tak langsung yang sangat nyata $(\mathrm{P}<0,01)$ dengan keberhasilan usaha kemitraan dan terlihat pengetahuan memiliki nilai hubungan keeratan secara tidak langsung yang paling tinggi $(0,148)$. Meskipun sikap tidak berhubungan langsung, sikap yang positif dapat mempengaruhi keberhasilan jika disertai dengan pengambilan keputusan yang baik. Sikap tidak dapat berdiri sendiri karena merupakan determinan perilaku yang berkaitan dengan persepsi dan motivasi (Inggriati, 2014).

\section{SIMPULAN}

Tingkat keberhasilan usaha kemitraan ayam ras pedaging di Kabupaten Tabanan berada pada tingkat sedang dengan capaian: tingkat kematian 5-7\%, ratarata indeks prestasi 300, bobot panen pada umur 30 hari rata-rata 1,55 kg/ekor dengan FCR 1,620, rata-rata pendapatan mencapai $\mathrm{Rp}$ 1.500-2.00o/ekor/periode dengankeuntunganbersihrata-rataRp700-1.00o/ekor/ periode. Sebagian besar peternak plasma di Kabupaten Tabanan sudah mampu melakukan pengambilan keputusan yang baik. Pengetahuan, sikap dan persepsi peternak plasma berpengaruh positif nyata terhadap pengambilan keputusan dalam manajemen usaha kemitraan ayam ras pedaging, sedangkan motivasi dan 
interaksi sosial tidak berpengaruh nyata. Pengambilan keputusan pada manajemen pemeliharaan berpengaruh positif nyata terhadap keberhasilan usaha kemitraan ayam ras pedaging. Pengambilan keputusan pada manajemen pemeliharaan secara langsung berpengaruh positif paling dominan terhadap keberhasilan usaha kemitraan dibandingkan pengetahuan, sikap, motivasi, persepsi dan interaksi sosial.

\section{UCAPAN TERIMA KASIH}

Pada kesempatan ini penulis mengucapkan terima kasih peternak plasma dan perusahaan kemitraan yang telah meluangkan waktunya untuk diwawancarai, sehingga penelitian dan penulisan artikel ilmiah ini dapat terlaksana.

\section{DAFTAR PUSTAKA}

Abdillah, W., dan Jogiyanto, H. M. 2015. PLS (Partial Least Square): Alternatif Structural Equation Modeling (SEM) dalam Penelitian Bisnis. Penebit Andi Offset, Yogyakarta.

Gerungan, W. A. 2010. Psikologi Sosial. PT. Refika Aditama, Bandung.

Hair, J., W. Black, B. Babin dan R. Anderson. 2011. "PLS
SEM: indeed a silver bullet". Journal of Marketing Theory and Practice, Volume 19 No 2: page 139-151.

Inggriati, N. W. T. 2014. Perilaku Peternak Sapi Bali Perbibitan dalam Sistem Penyuluhan di Bali. Disertasi. Program Pascasarjana Universitas Udayana, Denpasar.

Mulyana, D. 2007. Ilmu Komunikasi Suatu Pengantar. PT. Remaja Rosdakarya, Bandung.

Purnaningsih, N. 2006. Adopsi inovasi pola kemitraan agribisnis sayuran di Propinsi Jawa Barat. Disertasi. Program Pascasarjana Institut Pertanian Bogor, Bogor.

Saptana, R. dan Daryanto, A. 2013. Dinamika Kemitraan Usaha Agribisnis Berdaya saingdan Berkelanjutan. Pusat Sosial Ekonomi dan Kebijakan Pertanian.Badan Penelitian dan Pengembangan Pertanian, Kementerian Pertanian, Bogor.

Singarimbun, M. dan Effendi, S. 2006. Metode Penelitian Survai. LP3ES, Jakarta.

Sujak, A. 2007. Kepemimpinan Manajer: Eksistensi dalam Perilaku Organisasi. Penerbit Rajawali, Jakarta.

Suparta, N. 2001. Perilaku Agribisnis dan Kebutuhan Penyuluhan Peternak Ayam Ras Pedaging. Disertasi. Program Pascasarjana Institut Pertanian Bogor, Bogor.

Thoha, M. 2007. Kepemimpinan dalam Manajemen. Edisi 12. Raja Grafindo Persada, Jakarta. 